\title{
Research Article: On-farm evaluation of farming system modules for improving profitability and livelihood of small and marginal tribal farmers in high altitudes tribal zone of Andhra Pradesh
}

\author{
K. Tejeswara Rao, M.M.V. Srinivasa Rao and D. Nagarajuna
}

Article Chronicle:

Received :

24.03.2020;

Revised:

08.06.2020;

Accepted :

09.07.2020

\section{KEY WoRds :}

Integrated farming

systems,

Diversification,

Livestock,

Economics, B:C ratio

Author for correspondence :

K. Tejeswara Rao

All India Coordinated

Research Project on

Integrated Farming

Sysytems (A.N.G.R.A.U.),

Gajulurega, Vizianagram

(A.P.) India

Email: tejaseniorscientist

@gmail.com

See end of the article for

authors' affiliations
SUMMARY : Small and fragmented land holdings do not allow a farmer to keep independent farm resources like draught animals, tractors, bore wells/ tube wells and other sophisticated machineries for various cultural operations. Further, most of the inputs have become costly and out of reach of these resource poor farmers which has resulted farming as an uneconomic and unsustainable enterprise. To fulfil the basic needs of household including food (cereal, pulses, oilseeds, milk, fruit, honey, fish meat, etc.) for human, feed and fodder for animals and fuel and fibre for general use warrant an attention about integrated farming system. The emergence of integrated farming systems (IFS) has enabled us to develop a framework for an alternative development model to improve the feasibility of small sized farming operations in relation to larger ones. Integrated farming system is a commonly and broadly used word to explain a more integrated approach to farming as compared to monoculture approaches. AICRP-IFS, Seethampeta, ANGRAU centre implemented on farm research on "on-farm evaluation of farming system modules for improving profitability and livelihood of small and marginal farmers" with financial and technical assistance from Indian Institute of Farming System Research, Modipuram in 12 small and marginal tribal farmers' households in Seetampeta mandal of Srikkakulam district of Andhra Pradesh objectives of to address critical constraints of small and marginal farm holders for overall improvement of productivity and to increase the profitability of small and marginal households and ensure livelihood. By diversification in all enterprises farmers realized Rs. 62755, 65387, 82235 and 88967 gross returns and Rs.32125, 34117, 47075 and 49747 net returns was more than the bench mark Rs.46720, 47856, 58240 and Rs. 62376 with the additional interventions costs of Rs. 3770 in 2012-13, 2013-14, 2014-15 and 2015-16, respectively. Further, with integration of enterprises viz., Crops+Poultry, Crops+Dairy and Crops+Poultry+Dairy farmers realized Rs. 65387, 82235and 88967 gross returns and Rs.34117, 47075 and 49747 net returns when compared to crops only i.e., Rs. 62755 and Rs.32125, respectively. The increase income is attributed to increase in income from intervention in paddy crop and ragi crop, feeding of supplement feed to the cattle and also the introduction of Vanaraja and Rajshri back yard poultry birds. In addition to this not only due to diversification of existing enterprises, but also addition of enterprises in farming system modules. Gross income in all farming systems increased when compared to cropping system only. Gross income increased in crop - poultry farming system due to different modules from Rs. 47856/house hold to Rs. 65387/house hold with B: C ratio 2.09 and Gross income increased in crop - dairy farming system due to different modules from Rs. 58240/house hold 